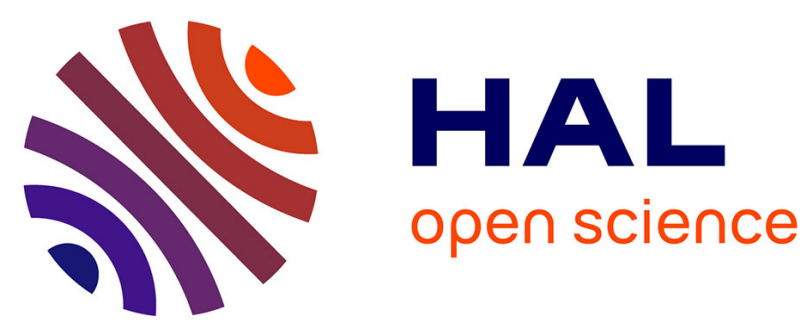

\title{
An innovative approach for the simultaneous quantitative screening of organic plastic additives in complex matrices in marine coastal areas
}

Javier Castro-Jiménez, Nuno Ratola

\section{- To cite this version:}

Javier Castro-Jiménez, Nuno Ratola. An innovative approach for the simultaneous quantitative screening of organic plastic additives in complex matrices in marine coastal areas. Environmental Science and Pollution Research, In press, 10.1007/s11356-020-08069-9 . hal-02497492

\section{HAL Id: hal-02497492 \\ https://hal.science/hal-02497492}

Submitted on 3 Mar 2020

HAL is a multi-disciplinary open access archive for the deposit and dissemination of scientific research documents, whether they are published or not. The documents may come from teaching and research institutions in France or abroad, or from public or private research centers.
L'archive ouverte pluridisciplinaire HAL, est destinée au dépôt et à la diffusion de documents scientifiques de niveau recherche, publiés ou non, émanant des établissements d'enseignement et de recherche français ou étrangers, des laboratoires publics ou privés. 


\title{
An innovative approach for the simultaneous quantitative screening of organic plastic additives in complex matrices in marine coastal areas
}

\author{
Javier Castro-Jiménez ${ }^{1}$ (D) Nuno Ratola ${ }^{2}$
}

Received: 12 July 2019 / Accepted: 11 February 2020

\begin{abstract}
Aiming the simultaneous determination of widely used organic plastic additives in complex marine matrices, this work proposes a fast and "green" analytical protocol based on quick, easy, cheap, effective, rugged, and safe (QuEChERS) technology. The validation of this innovative method on real matrices (i.e., sediments, mussel, fish, and Posidonia oceanica) indicated a general good performance in all of them for phthalate esters (PAEs), with low blank levels and average method recoveries varying from $54 \pm 11$ to $71 \pm 12 \%$. The best method performance for organophosphate ester (OPE) flame retardants and plasticizers was in biotic matrices (recoveries $52 \pm 31$ to $86 \pm 38 \%$ ). This application represents an innovative QuEChERS sequence of two dispersive solid-phase extraction (SPE) steps enabling this approach for the determination of important families of organic plastic additives in the marine environment. Indeed, our method allowed the fast screening and simultaneous determination of OPE and PAEs in various sites and matrices subject to different anthropogenic pressure in coastal NW Mediterranean Sea for the first time. $\sum_{7} \mathrm{PAE}$ and $\sum_{9} \mathrm{OPE}$ concentrations of 19-83 and 27-116 $\mathrm{ng} \mathrm{g}^{-1} \mathrm{dw}$ (fish), of 80-714 and 42-71 $\mathrm{ng} \mathrm{g}^{-1} \mathrm{dw}$ (mussels), of 192-908 and 47-151 $\mathrm{ng} \mathrm{g}^{-1} \mathrm{dw}$ (Posidonia oceanica), and of 11-328 and 4-10 $\mathrm{ng} \mathrm{g}^{-1} \mathrm{dw}$ (sediment) were measured, respectively. Our approach was sensible enough as to detect differences in the (bio)accumulation patterns of the target compounds in various species and/or sites. This application opens new perspectives for environmentally friendly marine environment monitoring and screening campaigns for organic plastic additives.
\end{abstract}

Keywords Organophosphate esters $\cdot$ Phthalates $\cdot$ QuEChERS $\cdot$ Marine vegetation $\cdot$ Biota $\cdot$ Sediments

Responsible editor: Roland Peter Kallenborn

Javier Castro-Jiménez

javier.castro-jimenez@mio.osupytheas.fr

Nuno Ratola

nrneto@ fe.up.pt

1 Aix Marseille Univ., University of Toulon, CNRS, IRD, Mediterranean Institute of Oceanography (MIO) UM 110, Marseille, France

2 LEPABE - Laboratory for Process Engineering, Environment, Biotechnology and Energy, Faculty of Engineering, University of Porto, Porto, Portugal

\section{Introduction}

Marine ecosystems, in particular coastal areas, are intricate yet delicate environments very sensitive to chemical contamination and generally under strong urban, agricultural, and industrial pressures (permanent or seasonal). One of the highest current concerns is on the environmental occurrence and potential effects of organic contaminants that could be released from plastic materials, due to the large accumulation of plastic waste in the marine environment (Jambeck et al. 2015). Organophosphate and phthalate esters (OPEs and PAEs, respectively) are among the most important organic plastic additives (Meeker et al. 2009; Hahladakis et al. 2018). Some OPEs and PAEs have been reported as hazardous chemicals and also classified (or suspected) endocrine disruptors (e.g., diethylhexyl phthalate, DEHP; tris-(2-chloro, 1-methylethyl) phosphate, TCPP) (van der Veen and de Boer 2012; Manikkam et al. 2013; Wei et al. 2015; Quinnies et al. 
2017). Although these contaminants of emerging concern are commonly detected in the aquatic environment, their occurrence in marine ecosystems is less studied (Wei et al. 2015; Net et al. 2015a; Hermabessiere et al. 2017). In addition, data in complex marine matrices like sediments and particularly living organisms is scarce. This is mostly due to the challenges of the analytical determinations, with frequent problems such as high matrix effects and contamination of samples, with extraction and clean-up as critical steps (Namieśnik 2002; Baduel et al. 2015; Ibáñez and Cifuentes 2017). Single or different combinations of extraction/clean-up techniques have been employed for the analysis of OPEs and PAEs in some solid marine matrices (mostly sediments) like Soxhlet, accelerated solvent extraction (ASE), microwave and ultrasonic extraction (MAE and USE, respectively), with alumina, silica, and Florisil among the most common clean-up phases (David et al. 2006; Net et al. 2015b; Pantelaki and Voutsa 2019). The data for marine organisms is scarce (Hu et al. 2016; Greaves and Letcher 2017), typically involves intricate sample cleanup procedures and the existing analytical protocols generally consider OPEs and PAEs separately. Aiming for the simplification of this type of analysis and the reduction of their environmental fingerprint (Gałuszka et al. 2013), we present here a fast and "green" method based on QuEChERS (quick, easy, cheap, effective, rugged, and safe) (Anastassiades et al. 2003) for the simultaneous assessment of OPEs and PAEs in various complex marine matrices. Namely, sediment, mussel, fish, and the seagrass Posidonia oceanica are all collected in the Mediterranean Sea, one of the major hotspots of plastic contamination in the world (Eriksen et al. 2014; Cózar et al. 2015). This strategy is innovative and represents an improvement to the current trends and state-of-the-art of the QuEChERS technology (Santana-Mayor et al. 2019) and to the multi-component quantification of emerging contaminants in marine ecosystems.

\section{Experimental}

\section{Solvents, standards, and QuEChERS materials}

Information on solvents, standards, and materials is available in Supporting Information (Text S1), together with additional details on compounds, GC/MS identification, and physicalchemical properties (Table S1).

\section{Samples}

Four different marine matrices collected in 2018 in the NW Mediterranean Sea were chosen in this study: Posidonia oceanica (leaves), an autochthonous seagrass, mussels, fish, and sediments. Posidonia oceanica and sediments were selected from two different locations with distinct anthropogenic signatures (Figure S1). The first sampling area is in the southern part of Marseille bay, not far from the touristic sea route between the city and the Frioul archipelago (sample named Frioul). The other area is under the influence of the Marseille's WWTP discharge (named WWTP-Cortiou). Mussels (Mytilus galloprovincialis) were taken in the wild (Figure $\mathrm{S} 1$ ) and also purchased in a supermarket (commercial). Fish adult individuals were chosen from two different species, Atlantic bonito (Sarda sarda, Bloch, 1793) and European hake (Merluccius merluccius, Linneaus, 1758) and were acquired in Marseille's fish market (dorsal muscle dissected for analyses). Both species are commercialized for human consumption and can be found both in the Atlantic and in the Mediterranean. All the samples were then frozen at $-20{ }^{\circ} \mathrm{C}$ and freeze-dried. Biotic samples were ground into a homogenized fine powder and sediments sieved $(500 \mu \mathrm{m})$ prior to analyses (see Text $\mathrm{S} 1$ for further details).

\section{General QuEChERS protocol}

Several experiments were conducted in this study, first to adapt a previously developed approach based on commercial QuEChERS to the target emerging contaminants and marine matrices and then to validate the final protocol. Typically, the QuEChERS base technique is composed of three main phases (Homem et al., 2013; Ribeiro et al. 2014): (i) a microscale extraction (in this case, sonication) of the matrix in a closed tube using an organic solvent; (ii) addition of anhydrous salts or buffers to the tube with the matrix and extract to promote the separation of phases and facilitate the partitioning of the analytes into the organic phase (first QuEChERS stage, Q1); (iii) transfer of the Q1 extract to a new tube containing appropriate sorbents to perform a dispersive-SPE used as a clean-up step to remove undesired components (second QuEChERS stage, Q2). The general QuEChERS protocol used in the current study is an adaptation of this approach.

A scheme is detailed in Fig. 1, and the final selection of clean-up phases is discussed on the "QuEChERS composition evaluation" section (Fig. 2). Briefly, all samples were spiked with surrogate-labelled standards (100 ng sample ${ }^{-1}$ ) (Table S1) and placed (0.5 g dw and $3 \mathrm{~g} \mathrm{dw}$ for biota and sediment, respectively) in centrifuge tubes. The corresponding solvent mix was then added $(10 \mathrm{~mL})$, as well as a small amount of activated copper for sediments only. The tubes were closed with Teflon liner caps, vortexed (1 min), and then ultrasound extracted $(10 \mathrm{~min})$. Then, the contents of Q1 were added to the extraction tubes and the mixture vortexed ( $3 \mathrm{~min}$ ) and centrifuged ( $5 \mathrm{~min}$ at $4000 \mathrm{rpm}$ ). The supernatant was transferred with pre-cleaned Pasteur pipettes to another tube containing the sorbents selected for Q2 and processed as above. Finally, the extract was concentrated to about $50 \mu \mathrm{L}$ using a gentle $\mathrm{N}_{2}$ stream and the syringe standards for quantification were added (100 ng sample ${ }^{-1}$ ) (Table S1). 


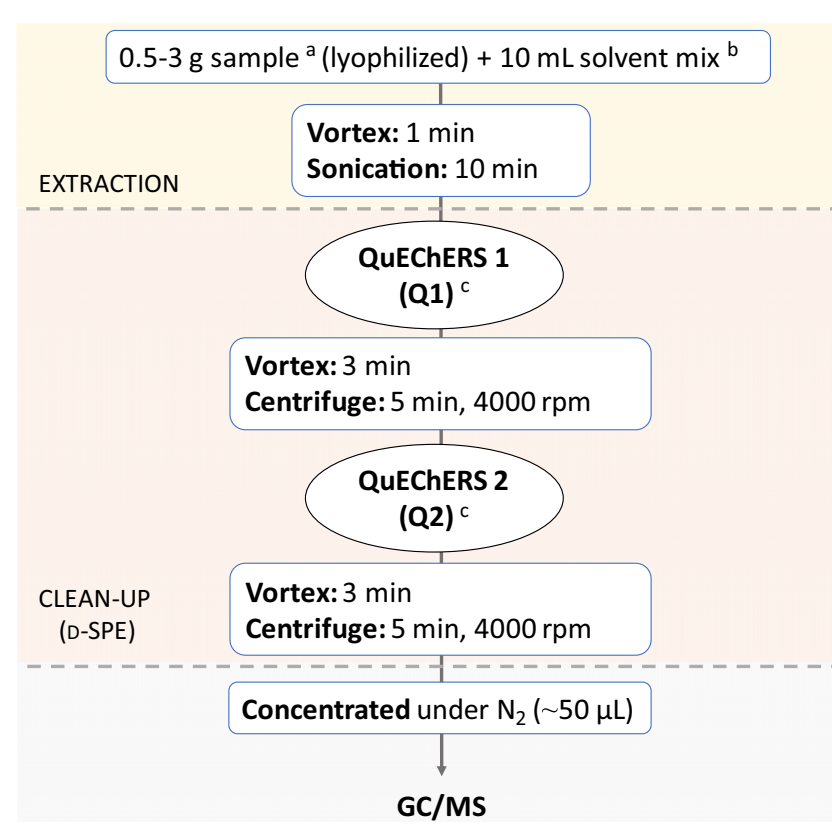

Fig. 1 General QuEChERS protocol used for the quantitative analysis of OPEs and PAEs. (a) Different sample amounts were used depending on the matrix, (b) different solvent combinations and (c) compositions of Q1 and Q2 were tested (see "QuEChERS composition evaluation" section)

\section{Instrumental analysis}

Samples were analyzed by gas chromatography coupled with mass spectrometry (GC/MS) for nine organophosphate esters and seven phthalate esters (Table S1), in selected ion monitoring (SIM) and electron impact (EI, $70 \mathrm{eV}$ ) modes. The separation was achieved in a $30 \mathrm{~m} \times 0.25 \mathrm{~mm}$ i.d. $\times 0.25 \mu \mathrm{m} \mathrm{HP}$ $5 \mathrm{MS}$ capillary column (Agilent $\mathrm{J} \& \mathrm{~W}$ ). All target contaminants were quantified by the internal standard (IS) procedure based on multi-level calibration curves. The injection volume

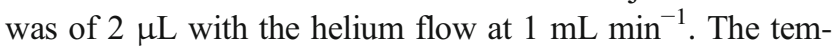
peratures of the MS transfer line, ion source, and quadrupole were 300,230 , and $150{ }^{\circ} \mathrm{C}$, respectively. Further details are presented in Text $\mathrm{S} 1$.

\section{Quality assurance/quality control}

Given the strong possibility of cross-contamination during OPE and PAE analysis, strict measures were taken to minimize it. The entire protocol was carried out in an ISO class 6 cleanroom for organic trace analysis. The use of plastic material was avoided at all times and all glassware was carefully cleaned, and baked at $450{ }^{\circ} \mathrm{C}$ for $6 \mathrm{~h}$. Florisil, alumina, and $\mathrm{MgSO}_{4}$ were also baked at $450{ }^{\circ} \mathrm{C}$ overnight before use. Method blanks considering all steps were made for each batch of analysis. Median blank levels in the real samples analyzed were generally low, varying from non-detected (n.d.) to $\sim 8 \mathrm{ng}$ depending on the compound and the extraction batch, with the exception of TCPP-2 which exhibited higher blank levels (69 ng) (Table S2). Results were blank corrected accordingly by subtracting the blank value of the specific batch. Chromatographic peaks were considered only with signal-tonoise ratio $\geq 10$. The instrumental LOQs obtained were at pg level, varying from 1 to $30 \mathrm{pg}$ for OPEs and from 1 to $10 \mathrm{pg}$ for PAEs (see Table S3 for further details).

\section{Results and discussion}

\section{Upgrading of commercial QuEChERS}

\section{Extraction solvent and material}

Preliminary experiments were conducted to adapt a protocol based on the commercial QuEChERS developed previously for the analysis of methylsiloxanes in marine vegetation (Rocha et al. 2019) to the extraction of OPEs and PAEs from the target matrices. The focus was on the effects of the extraction tube material and solvent mixtures on the background noise and blank levels, which are critical issues for the trace analysis of organic plastic additives. Polypropylene Falcon tubes $(\mathrm{PP}, 50 \mathrm{~mL})$ and glass centrifuge tubes $(30 \mathrm{~mL})$ were tested under five solvent conditions (in duplicate) with no samples or sorbents: (a) Hexane/DCM (1:1); (b) DCM; (c) DCM/acetone (2:1); (d) EtOAc; (e) DCM/EtOAc (1:1). The chromatograms were evaluated by tracking the presence of all target compounds, focusing on those normally showing blank problems (i.e., DEHP for PAEs and TCCP for OPEs) (Guo and Kannan 2012; Stubbings et al. 2017) (Table S4). Both DEHP and TCPP were found in all PP extracts, whereas TCPP was not found in the extracts from glass tubes. The
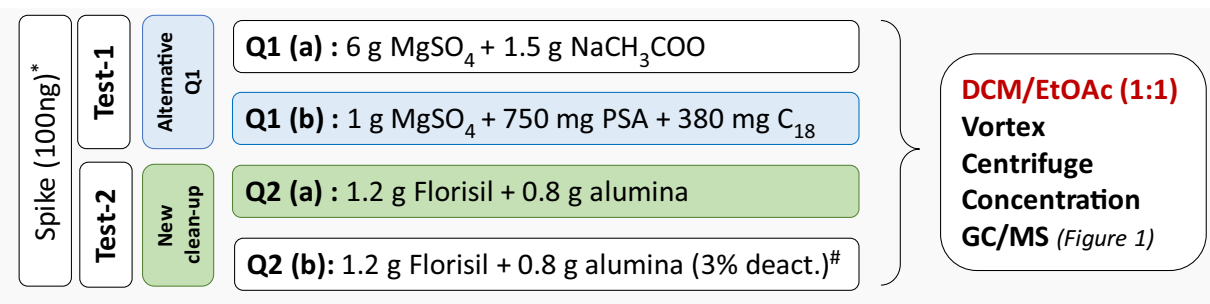

Fig. 2 Scheme illustrating the different QuEChERS combinations studied for the optimization of the general procedure for the analysis of OPE and PAEs in complex marine matrices. Asterisk indicates native and surrogate compounds were spiked at $100 \mathrm{ng}$ tube ${ }^{-1}$. Number sign indicates the alumina was deactivated using MQ water 
DEHP values were from 2 to 36 times higher in the extracts from PP compared with those of glass material (except in one assay with DCM/acetone (2:1) with similar values). In addition, chromatograms from the PP extracts of all solvent conditions showed considerably higher background noise (Figure S2). These facts confirm that the classic Falcon PP tubes used in QuEChERS protocols should not be used in the analyses of PAE and OPEs, nor probably for other organic plastic additives. In glass tubes, EtOAc and DCM/EtOAc (1:1) exhibited the lowest DEHP blank levels. However, since TDCP was found in one of the EtOAc replicates, the choice of the best solvent relied on DCM/EtOAc (1:1).

\section{QuEChERS composition evaluation}

A first test was performed to replicate the QuEChERS composition reported previously for marine vegetation (Rocha et al. 2019), but in this case using glass tubes (instead of polypropylene), lyophilized samples (instead of wet samples), and DCM/EtOAc (1:1) as extraction solvent. However, this approach failed to produce clean extracts. To improve the method, two different combinations, each of commonly used clean-up sorbents on the analysis of target compounds in environmental samples (van der Veen and de Boer 2012; Castro-Jiménez et al. 2018), were tested (in duplicate and with no sample) for Q1 and Q2 steps (Fig. 2). In each case, the sorbent combinations were inserted in glass tubes and spiked directly (100 ng) with target compounds (natives and surrogates) and extracted with DCM/EtOAc (1:1) following the general procedure described in the "General QuEChERS protocol" section (Fig. 1). Test-1 (for Q1): The original protocol developed for fresh matrices (Rocha et al. 2019) included a combination of sodium acetate $\left(\mathrm{NaCH}_{3} \mathrm{COO}\right)$ and anhydrous $\mathrm{MgSO}_{4}$ in Q1 stage (Q1-a). However, our new application considers freeze-dried samples in order to facilitate homogenization, sample handling, and comparability, and $\mathrm{NaCH}_{3} \mathrm{COO}$ could be not needed. This test evaluated the effect of the substitution of a traditional Q1 stage by a combination of anhydrous $\mathrm{MgSO}_{4}$, primary and secondary amine (PSA) and $\mathrm{C}_{18}$, which is typically used in commercial QuEChERS but on a second stage, resulting in an alternative Q1 (Q1-b) for this application. This modification makes way for a second cleanup step, not included in commercial QuEChERS, which would then become the second stage (Q2) for our application (Fig. 2). Test-2 (for Q2): In this step, the resulting extract from Q1 is added to a tube containing two possible combinations of Florisil and alumina (Q2-a with activated alumina and Q2-b with deactivated alumina) to evaluate a potential enhancement of the clean-up capacity of the entire protocol (Fig. 2).
Median recoveries ranged from 77 to $91 \%$ for PAEs and 52 to $67 \%$ for OPEs depending on the condition (Figure S3). Overall, for Q1, the results indicate that Q1-b (i.e., $1 \mathrm{~g}$ $\mathrm{MgSO}_{4}+0.75 \mathrm{~g} \mathrm{PSA}+0.38 \mathrm{~g} \mathrm{C}_{18}$ ) yield similar or better results than the common first step of QuEChERS approaches (Q1-a): $6 \mathrm{~g} \mathrm{MgSO}_{4}+1.5 \mathrm{~g} \mathrm{NaCH}_{3} \mathrm{COO}$, particularly for OPEs. Regarding Q2 (1.2 g Florisil $+0.8 \mathrm{~g}$ alumina), similar recoveries were obtained using activated (Q2-a) and 3\% deactivated alumina (Q2-b) for most compounds (Figure S3). Since the deactivation process is timeconsuming and may increase the variability of the results, it was decided to pursue with activated alumina. These results pointed towards the adoption of conditions Q1-b and Q2-a, which now represent an innovative QuEChERS sequence of two dispersive-SPE steps instead of the common salt/buffer (Q1) and dispersive-SPE (Q2) combination.

\section{Validation in marine matrices}

The application of the optimized QuEChERS protocol to real samples included validation via recovery and repeatability assays on Posidonia, mussels, fish (Sarda sarda), and sediments. Triplicate recovery tests were done at two spiking levels ( 25 and $100 \mathrm{ng}$ sample ${ }^{-1}$ ) with $0.5 \mathrm{~g}$ of dry sample, except for sediments where $3 \mathrm{~g}$ was used (Table 1). Results indicated acceptable average recoveries at both spiking levels in all samples both for PAEs ( $54 \pm 11$ to $71 \pm 12 \%$, average \pm SD) and for OPEs in biotic samples (52 \pm 31 to $86 \pm 38 \%$ ). Lower recoveries were obtained for OPEs in sediment samples, varying from $40 \pm 9$ to $41 \pm 6 \%$. Average $(n=3)$ relative standard deviations ranged from 3 to $10 \%$, indicating a good method repeatability (Table S5).

The use of simpler and faster techniques in the trace analysis of organic pollutants of emerging concern in complicated environmental matrices often requires a careful consideration regarding the potential reduction of performance (in terms of recovery, for instance) as opposed to the saving of resources and time and the reduction of harmful substances employed in the process (organic solvents, etc.). Our results and the wide scope of the protocol clearly justify its adoption. However, we acknowledge the possibility of future improvement of its validation parameters, particularly on its application on sediment for the OPE analysis.

\section{Screening of OPEs and PAEs in field samples}

The newly developed protocol was used to perform an initial screening of the presence of OPEs and PAEs in naturally contaminated samples from the four matrices in the study. $\sum_{7}$ PAE concentrations in sediment (11$\left.328 \mathrm{ng} \cdot \mathrm{g}^{-1} \mathrm{dw}\right)$ were $3-33$ times higher than $\sum_{9} \mathrm{OPE}$ levels (4-10 ng. $\mathrm{g}^{-1} \mathrm{dw}$ ) (Table S6). Higher PAE and OPE levels were generally found in the sample collected 
Table 1 Recoveries (average $\pm \mathrm{SD}$ ) for OPE and PAE extraction from four marine matrices at two spiking levels $\left(25\right.$ and $100 \mathrm{ng}$ sample $\left.{ }^{-1}\right)$

\begin{tabular}{|c|c|c|c|c|c|c|c|c|}
\hline \multirow{2}{*}{$\begin{array}{l}\text { AV R }(\%)(n=3) \\
\text { Spike level }\end{array}$} & \multicolumn{2}{|l|}{ Sediment } & \multicolumn{2}{|l|}{ Posidonia } & \multicolumn{2}{|l|}{ Mussel } & \multicolumn{2}{|l|}{ Fish } \\
\hline & $25 \mathrm{ng}$ & $100 \mathrm{ng}$ & $25 \mathrm{ng}$ & $100 \mathrm{ng}$ & $25 \mathrm{ng}$ & $100 \mathrm{ng}$ & $25 \mathrm{ng}$ & $100 \mathrm{ng}$ \\
\hline \multicolumn{9}{|c|}{ Organophosphate esters (OPEs) } \\
\hline ТPP & $28.9 \pm 2.9$ & $31.4 \pm 1.0$ & $45.3 \pm 2.5$ & $32.7 \pm 0.7$ & $57.5 \pm 4.7$ & $34.2 \pm 2.8$ & $37.3 \pm 2.6$ & $32.1 \pm 0.7$ \\
\hline TiBP & $34.4 \pm 3.0$ & $40.3 \pm 1.2$ & $43.9 \pm 2.8$ & $42.3 \pm 2.7$ & $84.3 \pm 6.1$ & $49.1 \pm 4.4$ & $79.1 \pm 1.4$ & $53.1 \pm 1.6$ \\
\hline $\mathrm{TnBP}$ & $35.2 \pm 2.3$ & $38.7 \pm 1.5$ & $68.1 \pm 2.0$ & $47.2 \pm 0.1$ & $74.5 \pm 8.4$ & $45.4 \pm 2.0$ & $69.6 \pm 1.2$ & $48.1 \pm 1.3$ \\
\hline TCEP & $57.0 \pm 16.9$ & $32.0 \pm 0.8$ & $26.3 \pm 4.5$ & $24.3 \pm 2.3$ & $44.4 \pm 3.0$ & $28.5 \pm 2.9$ & $26.4 \pm 4.8$ & $22.9 \pm 1.5$ \\
\hline ТCРP* & $43.1 \pm 4.3$ & $43.8 \pm 2.8$ & $18.0 \pm 4.9$ & $45.2 \pm 7.8$ & $101.8 \pm 145$ & $34.5 \pm 2.8$ & $37.1 \pm 6.3$ & $32.6 \pm 1.3$ \\
\hline TDCP & $48.5 \pm 1.5$ & $45.5 \pm 2.3$ & $135.5 \pm 0.3$ & $60.1 \pm 1.5$ & $139.9 \pm 3.1$ & $58.7 \pm 6.5$ & $29.8 \pm 1.3$ & $37.7 \pm 2.1$ \\
\hline $\mathrm{TPhP}$ & $45.1 \pm 3.0$ & $43.8 \pm 0.8$ & $41.6 \pm 2.9$ & $42.4 \pm 2.2$ & $44.1 \pm 2.9$ & $40.6 \pm 2.1$ & $49.3 \pm 2.7$ & $45.0 \pm 1.7$ \\
\hline EHDPP & $37.8 \pm 3.3$ & $50.1 \pm 2.2$ & $72.2 \pm 4.5$ & $71.1 \pm 2.2$ & $78.3 \pm 4.8$ & $67.7 \pm 5.3$ & $73.8 \pm 2.4$ & $70.2 \pm 3.8$ \\
\hline TEHP & $31.5 \pm 0.7$ & $44.4 \pm 2.9$ & $151.4 \pm 10.4$ & $137.2 \pm 0.5$ & $148.0 \pm 20.2$ & $125.6 \pm 12.8$ & $133.4 \pm 3.1$ & $126.5 \pm 0.4$ \\
\hline Average OPEs & $40.2 \pm 9.0$ & $41.1 \pm 6.2$ & $66.9 \pm 46.8$ & $55.8 \pm 33.4$ & $85.9 \pm 37.9$ & $53.8 \pm 29.7$ & $59.5 \pm 33.9$ & $52.0 \pm 31.2$ \\
\hline D27-TBP & $35.1 \pm 2.3$ & $36.2 \pm 0.6$ & $56.2 \pm 1.8$ & $56.2 \pm 1.1$ & $57.7 \pm 1.8$ & $52.9 \pm 9.1$ & $57.3 \pm 1.2$ & $57.0 \pm 1.4$ \\
\hline D15-TDCP & $37.6 \pm 1.8$ & $38.0 \pm 0.4$ & $70.7 \pm 1.0$ & $68.9 \pm 2.0$ & $78.0 \pm 1.3$ & $65.5 \pm 14.3$ & $71.8 \pm 1.5$ & $71.1 \pm 2.2$ \\
\hline \multicolumn{9}{|c|}{ Phthalic acid esters (PAEs) } \\
\hline $\mathrm{DMP}$ & $37.3 \pm 3.6$ & $47.5 \pm 5.1$ & $66.7 \pm 2.2$ & $46.1 \pm 2.6$ & $73.8 \pm 1.3$ & $48.9 \pm 2.8$ & $73.5 \pm 1.2$ & $57.9 \pm 2.7$ \\
\hline DEP & $51.5 \pm 18.4$ & $46.5 \pm 0.8$ & $61.1 \pm 3.9$ & $46.0 \pm 3.0$ & $52.2 \pm 1.7$ & $46.3 \pm 1.7$ & $48.8 \pm 1.2$ & $51.4 \pm 2.8$ \\
\hline DiBP & $53.7 \pm 7.2$ & $59.3 \pm 1.5$ & $44.8 \pm 7.4$ & $42.7 \pm 1.1$ & $62.4 \pm 0.6$ & $51.3 \pm 0.7$ & $55.0 \pm 0.7$ & $54.0 \pm 2.1$ \\
\hline $\mathrm{DnBP}$ & $54.6 \pm 2.8$ & $67.5 \pm 1.1$ & $\mathrm{n} \cdot \mathrm{r} \pm \mathrm{n} \cdot \mathrm{r}$ & $\mathrm{n} . \mathrm{r} \pm \mathrm{n} \cdot \mathrm{r}$ & $75.8 \pm 19.9$ & $52.1 \pm 6.5$ & $57.6 \pm 5.1$ & $53.2 \pm 3.5$ \\
\hline $\mathrm{BBzP}$ & $54.9 \pm 11.3$ & $48.0 \pm 3.0$ & $86.8 \pm 2.4$ & $64.5 \pm 2.0$ & $91.6 \pm 1.8$ & $53.5 \pm 1.8$ & $90.7 \pm 1.7$ & $60.0 \pm 2.4$ \\
\hline DEHP & $75.4 \pm 31.2$ & $61.0 \pm 4.3$ & $56.5 \pm \mathrm{n} . \mathrm{r}$ & $59.3 \pm 40.1$ & $72.0 \pm 0.0$ & $63.7 \pm 8.4$ & $55.3 \pm 4.5$ & $50.5 \pm 2.0$ \\
\hline $\mathrm{DnOP}$ & $49.2 \pm 3.9$ & $55.7 \pm 0.5$ & $82.3 \pm 2.4$ & $77.9 \pm 1.5$ & $70.3 \pm 0.8$ & $69.8 \pm 1.6$ & $76.7 \pm 1.9$ & $76.3 \pm 4.3$ \\
\hline Average PAEs & $53.8 \pm 11.3$ & $55.1 \pm 8.1$ & $66.4 \pm 15.9$ & $56.1 \pm 13.7$ & $71.2 \pm 12.1$ & $55.1 \pm 8.5$ & $65.4 \pm 15.2$ & $57.6 \pm 8.9$ \\
\hline D4-DnBP & $49.3 \pm 2.3$ & $51.8 \pm 0.4$ & $65.5 \pm 0.7$ & $66.5 \pm 1.9$ & $68.8 \pm 1.8$ & $62.6 \pm 5.0$ & $64.1 \pm 1.9$ & $64.6 \pm 2.4$ \\
\hline
\end{tabular}

*TCPP values correspond to the most abundant isomer, TCPP-1; n.r., not reported due to analytical problems

in the WWTP vicinity (Cortiou) compared with Frioul (Fig. 3(a, b)), particularly for DEHP (76 times higher). PAE and OPE total concentrations were dominated by DEHP and TCPP in Cortiou, respectively, while DiBP and EHDPP were more abundant in Frioul. On the contrary, $\sum_{7}$ PAE concentrations ( $908 \mathrm{ng} \mathrm{g}^{-1} \mathrm{dw}$ ) in Posidonia oceanica were 19-fold higher than $\sum_{9}$ OPE levels (47 $\mathrm{ng} \mathrm{g}^{-1} \mathrm{dw}$ ) in Frioul, while similar total concentrations were obtained near the WWTP for PAEs and OPEs (192 and $151 \mathrm{ng} \mathrm{g}^{-1} \mathrm{dw}$, respectively), pointing to different environmental sources and accumulation rates. DEHP dominated in both sites, while TCPP was one of the most abundant OPEs but prevailed only in Frioul (Fig. 3(c, d)).

In fish samples, $\sum_{7} \mathrm{PAE}$ and $\sum_{9} \mathrm{OPE}$ concentrations were similar, varying from 19 to $83 \mathrm{ng} \mathrm{g}^{-1} \mathrm{dw}$, and from 27 and $116 \mathrm{ng} \mathrm{g}^{-1} \mathrm{dw}$, respectively (Table S6). However, the bioaccumulation patterns were different, with individual OPEs (dominated by TDCP) at higher concentrations in the Atlantic bonito, while PAEs were generally more abundant in the European hake, with DnBP predominating (Fig. 3(e, $\mathrm{f})$ ). These results suggest different biomagnification potential of the two families of organic plastic additives studied. $\sum_{7}$ PAE concentrations in mussel (80-714 $\mathrm{ng} \mathrm{g}^{-1} \mathrm{dw}$ ) were 2-10 times higher than $\sum_{9} \mathrm{OPE}\left(42-70 \mathrm{ng} \mathrm{g}^{-1} \mathrm{dw}\right.$ ) (Table S6), indicating a generally higher potential of bioaccumulation for phthalates in this organism. Wild mussel exhibited similar or higher levels than commercial mussels for all PAEs, particularly DEHP (12fold higher) (Fig. 3(g, h)). This trend was not so clear for OPEs, with higher values in commercial mussel for some OPEs like TCEP and EHDPP. The mandatory depuration process for mussel commercialization for health safety guidelines (Lee et al. 2008) could result in a general contaminant reduction in the organism and partially explain these results, particularly for PAEs. OPEs have been reported as persistent (Wei et al. 2015) and may not be affected at the same rate for the depuration process.

\section{Conclusions}

Our study points to QuEChERS as a valid approach for the simultaneous quantitative screening of OPE and PAE in 


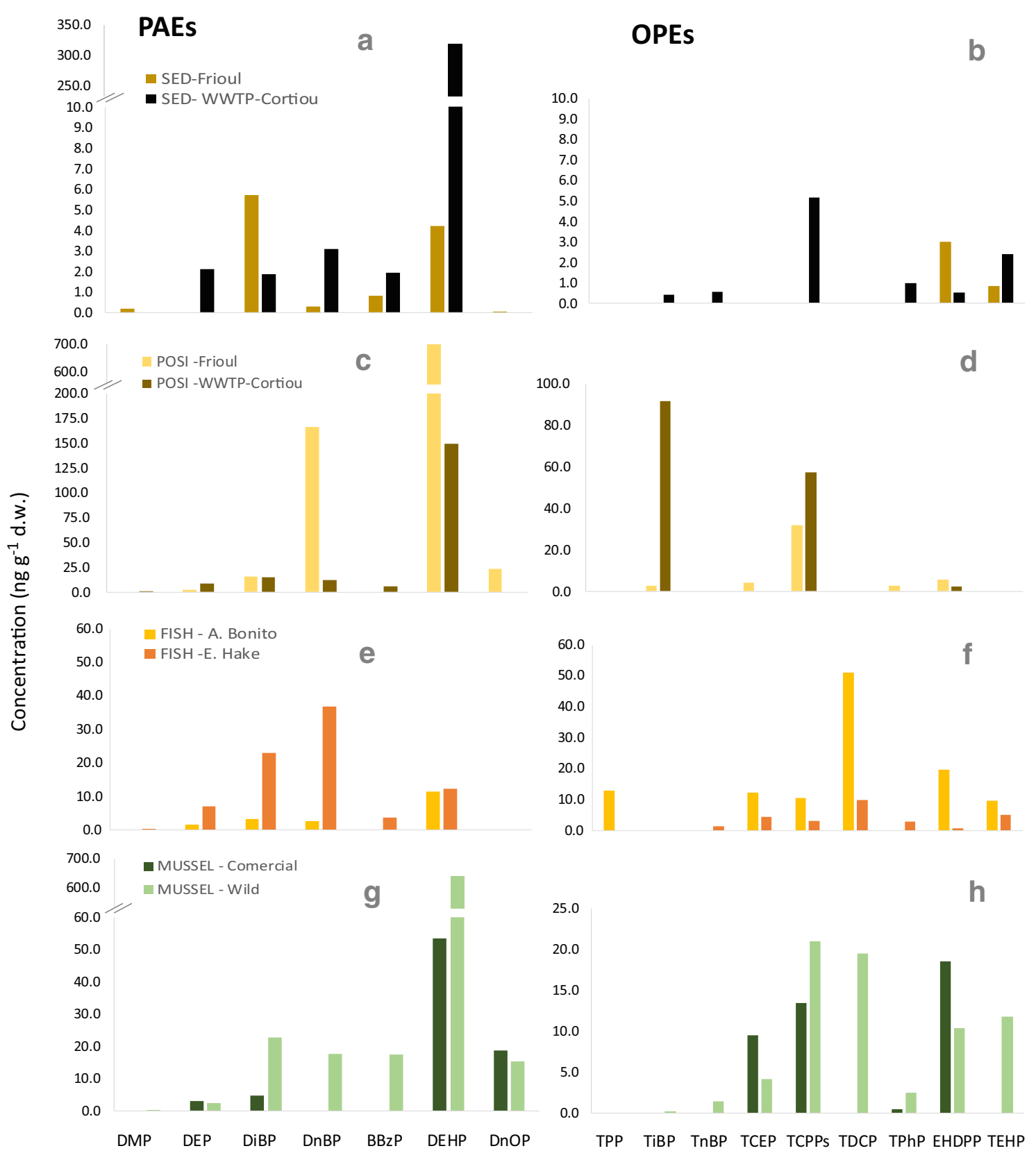

Fig. 3 OPE and PAE concentrations in sediment, Posidonia oceanica, fish, and mussel samples from NW Mediterranean Sea

complex marine matrices. However, a number of modifications in commercial QuEChERS are required for this application, like the use of glass tubes instead of classical polypropylene Falcon tubes and the introduction of additional cleanup phases like Florisil and alumina in the protocol. This application represents an innovative QuEChERS sequence of two dispersive-SPE steps enabling this approach for the determination of important families of organic plastic in the marine environment. Indeed, even if a limited number of samples were analyzed in this work, the developed method allowed the simultaneous determination of OPE and PAEs in various matrices and sites under different anthropogenic pressure in coastal NW Mediterranean Sea (fish, mussel, and Posidonia levels assessed for the first time). Our innovative approach was sensible enough as to detect differences in the (bio)accumulation patterns of the target compounds in various species and/or sites, launching new perspectives for more sustainable monitoring and screening strategies to address organic plastic additives in the marine environment.

Acknowledgments The authors wish to thank Sandrine Ruitton and Melanie Ourgaud for providing the Posidonia oceanica samples, Daniela Banaru for the fish samples, and Etien Castro for the wild mussel samples. Richard Sempéré is acknowledged for giving access to the analytical facilities necessary to develop this research. 
Funding information This work was financially supported by the Labex OT-Med - Project ECoMarE (ANR-11-LABX-0061), funded by the French Government "Investissements d'Avenir" (ANR) through the A*MIDEX project (no. ANR-11-IDEX-0001-02). Other financial support includes (i) French Water Agency trough the project CAREMED; (ii) Project UID/EQU/00511/2019 - Laboratory for Process Engineering, Environment, Biotechnology and Energy - LEPABE funded by national funds through FCT/MCTES (PIDDAC); (iii) Project "LEPABE-2-ECOINNOVATION" - NORTE-01-0145-FEDER-000005, funded by Norte Portugal Regional Operational Programme (NORTE 2020), under PORTUGAL 2020 Partnership Agreement, through the European Regional Development Fund (ERDF); (iv) Investigator FCT contract IF/01101/2014 (Nuno Ratola). The project leading to this publication has received funding from European FEDER Fund under project 116639417.

\section{References}

Anastassiades M, Lehotay SJ, Tajnbaher D, Schenck FJ (2003) Fast and easy multiresidue method employing acetonitrile extraction/partitioning and dispersive solid-phase extraction for the determination of pesticide residues in produce. $\mathrm{J}$ AOAC Int 86:412-431

Baduel C, Mueller JF, Tsai H, Gomez Ramos MJ (2015) Development of sample extraction and clean-up strategies for target and non-target analysis of environmental contaminants in biological matrices. J Chromatogr A 1426:33-47. https://doi.org/10.1016/j.chroma.2015. 11.040

Castro-Jiménez J, Barhoumi B, Tedetti M, Sempéré R (2018) Atmospheric particle-bound organophosphate ester flame retardants and plasticizers in a North African Mediterranean coastal city (Bizerte, Tunisia). Sci Total Environ 642:383-393. https://doi.org/ 10.1016/j.scitotenv.2018.06.010

Cózar A, Sanz-Martín M, Martí E, González-Gordillo JI, Ubeda B, Gálvez JÁ, Duarte CM (2015) Plastic accumulation in the Mediterranean Sea. PLoS One 10:e0121762. https://doi.org/10. 1371/journal.pone. 0121762

David F, Sandra P, Tienpont B, Vanwalleghem F, Ikonomou M (2006) Analytical methods review. In: Staples C.A. (eds) Series anthropogenic compounds. The Handbook of Environmental Chemistry, vol 3Q. Springer, Berlin, Heidelberg

Eriksen M, Lebreton LCM, Carson HS, Thiel M, Moore CJ, Borrero JC, Galgani F, Ryan PG, Reisser J (2014) Plastic pollution in the world's oceans: more than 5 trillion plastic pieces weighing over 250,000 tons afloat at sea. PLoS One 9:e111913. https://doi.org/10.1371/ journal.pone. 0111913

Gałuszka A, Migaszewski Z, Namieśnik J (2013) The 12 principles of green analytical chemistry and the significance mnemonic of green analytical practices. Trends Anal Chem 50:78-84. https://doi.org/ 10.1016/j.trac.2013.04.010

Greaves AK, Letcher RJ (2017) A review of organophosphate esters in the environment from biological effects to distribution and fate. Bull Environ Contam Toxicol 98:2-7. https://doi.org/10.1007/s00128016-1898-0

Guo Y, Kannan K (2012) Challenges encountered in the analysis of phthalate esters in foodstuffs and other biological matrices. Anal Bioanal Chem 404:2539-2554. https://doi.org/10.1007/s00216012-5999-2

Hahladakis JN, Velis CA, Weber R, Iacovidou E, Purnell P (2018) An overview of chemical additives present in plastics: migration, release, fate and environmental impact during their use, disposal and recycling. J Hazard Mater 344:179-199. https://doi.org/10.1016/j. jhazmat.2017.10.014

Hermabessiere L, Dehaut A, Paul-Pont I, Lacroix C, Jezequel R, Soudant P, Duflos G (2017) Occurrence and effects of plastic additives on marine environments and organisms: a review. Chemosphere 182: 781-793. https://doi.org/10.1016/j.chemosphere.2017.05.096

Homem V, Silva JA, Cunha C, Alves A, Santos L (2013) New analytical method for the determination of musks in personal care products by Quick, Easy, Cheap, Effective, Rugged, and Safe extraction followed by GC-MS. J Sep Sci 36:2176-2184. https://doi.org/10.1002/ jssc. 201300190

Hu X, Gu Y, Huang W, Yin D (2016) Phthalate monoesters as markers of phthalate contamination in wild marine organisms. Environ Pollut 218:410-418. https://doi.org/10.1016/j.envpol.2016.07.020

Ibáñez E, Cifuentes A (2017) Comprehensive analytical chemistry green extraction techniques: principles. Elsevier, Advances and Applications

Jambeck JR, Geyer R, Wilcox C, Siegler TR, Perryman M, Andrady A, Narayan R, Law KL (2015) Plastic waste inputs from land into the ocean. Science 347:768-771. https://doi.org/10.1126/science. 1260352

Lee R, Lovatelli A, Ababouch L (2008) Bivalve depuration: fundamental and practical aspects. FAO Fisheries Technical Paper 511. Food and Agriculture Organization of the United Nations, ISBN 978-92-5106006-3. Rome, Italy

Manikkam M, Tracey R, Guerrero-Bosagna C, Skinner MK (2013) Plastics derived endocrine disruptors (BPA, DEHP and DBP) induce epigenetic transgenerational inheritance of obesity, reproductive disease and sperm epimutations. PLoS One 8:e55387. https://doi.org/ 10.1371/journal.pone.0055387

Meeker JD, Sathyanarayana S, Swan SH (2009) Phthalates and other additives in plastics: human exposure and associated health outcomes. Phil Trans R Soc B 364:2097-2211. https://doi.org/10. 1098/rstb.2008.0268

Namieśnik J (2002) Trace analysis - challenges and problems. Crit Rev Anal Chem 32:271-300. https://doi.org/10.1080/ 10408340290765579

Net S, Delmont A, Sempéré R, Paluselli A, Ouddane B (2015b) Reliable quantification of phthalates in environmental matrices (air, water, sludge, sediment and soil): a review. Sci Total Environ 515-516:162-180. https://doi.org/10.1016/j.scitotenv. 2015.02.013

Net S, Sempéré R, Delmont A, Paluselli A, Ouddane B (2015a) Occurrence, fate, behavior and ecotoxicological state of phthalates in different environmental matrices. Environ Sci Technol 49:40194035. https://doi.org/10.1021/es505233b

Pantelaki I, Voutsa D (2019) Organophosphate flame retardants (OPFRs): a review on analytical methods and occurrence in wastewater and aquatic environment. Sci Total Environ 649:247-263. https://doi. org/10.1016/j.scitotenv.2018.08.286

Quinnies KM, Harris EP, Snyder RW, Sumner SS, Rissman EF (2017) Direct and transgenerational effects of low doses of perinatal di-(2ethylhexyl) phthalate (DEHP) on social behaviors in mice. PLoS One 12:e0171977. https://doi.org/10.1371/journal.pone.0171977

Ribeiro C, Ribeiro AR, Maia AS, Gonçalves VMF, Tiritan ME (2014) New trends in sample preparation techniques for environmental analysis. Crit Rev Anal Chem 44:142-185. https://doi.org/10. 1080/10408347.2013.833850

Rocha F, Homem V, Castro-Jiménez J, Ratola N (2019) Marine vegetation analysis for the determination of volatile methylsiloxanes in coastal areas. Sci Total Environ 650:2364-2373. https://doi.org/10. 1016/j.scitotenv.2018.10.012

Santana-Mayor A, Socas-Rodríguez B, Herrera-Herrera AV, RodríguezDelgado MA (2019) Current trends in QuEChERS method. A versatile procedure for food, environmental and biological analysis. 
Trends Anal Chem 116:214-235. https://doi.org/10.1016/j.trac. 2019.04.018

Stubbings WA, Riddell N, Chittim B, Venier M (2017) Challenges in the analyses of organophosphate esters. Environ Sci Technol Lett 4: 292-297. https://doi.org/10.1021/acs.estlett.7b00195

van der Veen I, de Boer J (2012) Phosphorus flame retardants: properties, production, environmental occurrence, toxicity and analysis. Chemosphere 88:1119-1153. https://doi.org/10.1016/j. chemosphere.2012.03.067
Wei G-L, Li D-Q, Zhuo M-N, Liao Y-S, Xie Z-Y, Guo T-L, Li J-J, Zhang S-Y, Liang Z-Q (2015) Organophosphorus flame retardants and plasticizers: sources, occurrence, toxicity and human exposure. Environ Pollut 196:29-46. https://doi.org/10.1016/j.envpol.2014. 09.012 